\title{
Cardiotoxicity and Cardioprotection in Childhood Cancer
}

\author{
Steven E. Lipshultz ${ }^{a-c}$ Peter Sambatakos ${ }^{a, b}$ Michael Maguire ${ }^{a, b}$ \\ Ruchika Karnik $^{a, b}$ Samuel W. Ross ${ }^{a}$ b Vivian I. Franco ${ }^{a}$ Tracie L. Miller ${ }^{a, b}$ \\ ${ }^{a}$ Department of Pediatrics, University of Miami Miller School of Medicine, and b Holtz Children's Hospital, Jackson \\ Health System, Miami, Fla., and 'Department of Pediatrics, Wayne State University School of Medicine and \\ Children's Hospital of Michigan, Detroit, Mich., USA
}

\section{Key Words \\ Cardioprotection · Cardiotoxicity · Childhood cancer survivors}

\begin{abstract}
Children diagnosed with cancer are now living longer as a result of advances in treatment. However, some commonly used anticancer drugs, although effective in curing cancer, can also cause adverse late effects. The cardiotoxic effects of anthracycline chemotherapy, such as doxorubicin, and radiation can cause persistent and progressive cardiovascular damage, emphasizing a need for effective prevention and treatment to reduce or avoid cardiotoxicity. Examples of risk factors for cardiotoxicity in children include higher anthracycline cumulative dose, higher dose of radiation, younger age at diagnosis, female sex, trisomy 21 and black race. However, not all who are exposed to toxic treatments experience cardiotoxicity, suggesting the possibility of a genetic predisposition. Cardioprotective strategies under investigation include the use of dexrazoxane, which provides short- and long-term cardioprotection in children treated with doxorubicin without interfering with oncological efficacy, the use of less toxic anthracycline derivatives and nutritional supplements. Evidence-based monitoring and screening are need-
\end{abstract}

ed to identify early signs of cardiotoxicity that have been validated as surrogates of subsequent clinically significant cardiovascular disease before the occurrence of cardiac damage, in patients who may be at higher risk.

(c) 2014 S. Karger AG, Basel

\section{Introduction}

In the 1970s, the 5-year survival rate of children diagnosed with cancer before the age of 15 years was less than $60 \%$ [1]. As of 2010 , it is $83 \%$, resulting in an estimated 379,000 survivors of childhood cancer in the USA $[1,2]$. Although increased survival is promising, it is not free of consequences. These young survivors are in a developmental stage that makes them particularly vulnerable to adverse health effects from the potentially toxic anticancer treatments, which become apparent years later. More than $70 \%$ of childhood cancer survivors will experience a chronic health condition within the first 30 years after diagnosis [3]. Furthermore, cardiovasculature-related disease is the leading cause of morbidity and mortality after cancer recurrence and secondary malignancies in these survivors [3-5]. By the age of 45 years, the cumulative incidence of coronary artery disease, heart failure,

\section{KARGER}

E-Mail karger@karger.com

www.karger.com/aha
C 2014 S. Karger AG, Base

$0001-5792 / 14 / 1324-0391 \$ 39.50 / 0$
Steven E. Lipshultz, MD

Department of Pediatrics, Wayne State University School of Medicine Children's Hospital of Michigan, 3901 Beaubien Blvd., Suite 1K40 Detroit, MI 48201 (USA)

E-Mail slipshultz@med.wayne.edu 
valvular disease and arrhythmia among survivors is 5.3, $4.8,1.5$ and $1.3 \%$, respectively, whereas the cumulative incidence for each among siblings is much lower: $0.9,0.3$, 0.1 and $0.4 \%$, respectively [6].

Anthracyclines commonly used to treat hematological malignancies and solid tumors are effective but may cause persistent and progressive cardiovascular damage [7]. Furthermore, the risk increases when used in combination with radiation therapy $[4,8]$. This review describes the mechanisms and course of anthracycline and radiation-induced cardiotoxicity and its risk factors in childhood cancer survivors, and discusses cardioprotective strategies to prevent or reduce long-term cardiac dysfunction.

\section{Mechanisms of Anthracycline-Induced Cardiotoxicity}

Anthracyclines, such as doxorubicin, epirubicin and daunorubicin, have substantially contributed to the improved cancer survival rates over the past 25 years in both adults and children [9]. These drugs have a range of anticancer properties that include preventing cell replication through DNA basepair intercalation and disrupting DNA uncoiling through inhibition of topoisomerase 2 activity. However, anthracyclines bind cellular membranes, which may negatively impact ion flow transport and form intracellular free radicals, which can further damage the cell [10].

Despite extensive research, the exact mechanism by which anthracyclines cause cardiotoxicity is still not fully known. Hypotheses include decreased ATP production as a consequence of decreased protein expression, impaired or destroyed mitochondria, and increased oxidative stress [10]. The oxidative stress hypothesis is the most commonly accepted hypothesis. Anthracyclines can form complexes with intracellular iron, which results in free radical formation, leading to the depletion of sulfhydrylcontaining peptides, lipid peroxidation and DNA damage [10]. The heart is thought to be particularly sensitive to this stress as a result of an abundance of mitochondria in cardiomyocytes, which include high concentrations of cardiolipin. Cardiolipin's high affinity for anthracyclines allows the drugs to enter cardiomyocytes passively and accumulate in intracellular fluids to concentrations several hundred times higher than that in extracellular fluids [11]. Additionally, the heart has a reduced ability to scavenge free radicals created by the anthracyclines, given that there are lower concentrations than is normally present of catalase and glutathione peroxidase in the presence of anthracyclines [10]. The increased stress and reduced free radical scavenging leads to cardiomyocyte-damaged DNA, reduced protein expression, damage to the cardiac sarcomere, destruction of myofilaments giving way to cell and organ damage, and left ventricular (LV) diastolic dysfunction with impaired contractility $[9,10]$.

\section{Mechanisms of Radiotherapy-Induced Cardiotoxicity}

Utilizing chemotherapy and radiation therapy together has been shown to improve oncological outcomes in many cancer patients, and about half of these patients now receive some amount of radiation [9]. However, much like the chemotherapeutic drugs, radiotherapy can also cause cardiotoxic side effects: myocardial fibrosis, cardiomyopathy, early coronary disease, and valvular and electrophysiological dysfunction [9]. The cardiotoxicity is believed to be caused by acute injury and inflammation leading to long-term myocardial fibrosis [10]. The risk of these cardiotoxic side effects increases two- to sixfold in patients receiving substantial chest radiation [12]. Cardiotoxicity from radiation is also dose dependent and correlates with the area of the heart exposed and the radiological technique used, as well as the patient's age, with a greater incidence in younger patients [9]. Patients receiving more than 1,500-3,500 cGy show an increased risk for cardiac disease, with high-level doses associated with myocardial ischemia as soon as 12 years after treatment [12].

\section{Cardiotoxicity Risk Factors}

Not every cancer survivor treated with anthracyclines and radiation experiences cardiotoxicity, but identifying risk factors may still help to determine which patients are at higher risk. These risk factors might help guide treatment and help clinicians determine appropriate followup intervals.

The risk of cardiotoxicity increases with a higher anthracycline cumulative dose. Cumulative doses greater than $500 \mathrm{mg} / \mathrm{m}^{2}$ have been linked to early congestive heart failure [13]. In a study by Nysom et al. [14], after a median of 8.1 years since the end of anthracycline therapy, patients who received cumulative doses between 244 and $550 \mathrm{mg} / \mathrm{m}^{2}$ experienced late anthracycline-related cardiotoxicity, as evidenced by depressed LV fractional shortening and increased LV dimension, whereas these conditions did not occur in 3 other cohorts who received 
relatively lower doses $\left(0-23,45\right.$ and $\left.73-301 \mathrm{mg} / \mathrm{m}^{2}\right)$. According to another recent study in adolescent patients, about 13 years after treatment, subclinical events occurred in about $30 \%$ of the patients, even at doses of 180 $240 \mathrm{mg} / \mathrm{m}^{2}$ [15]. These findings suggest that there is no safe dose of anthracyclines. Even doses as low as $100 \mathrm{mg} /$ $\mathrm{m}^{2}$ have been associated with reduced cardiac function $[14,16,17]$.

Younger age at diagnosis is also associated with anthracycline-induced cardiotoxicity $[18,19]$. Children less than 4 years of age at anthracycline exposure showed an increased risk of LV dysfunction [7]. Females have a higher risk of anthracycline-induced cardiotoxicity than do males [20]. Also, survivors with trisomy 21 are at an increased risk for LV dysfunction, even when patients with congenital cardiovascular abnormalities are excluded [21]. A number of other risk factors exist as well that will not be covered here such as preexisting risk factors for or the presence of cardiovascular disease, and noncardiac medical conditions that increase the risk of cardiovascular disease, including but not limited to endocrinopathies, infections, inflammatory conditions, obesity and metabolic diseases, failure to thrive, sedentary lifestyle, pulmonary disease, musculoskeletal disease, renal disease, hepatic disease, concomitant or prior medication usage (licit and illicit), a history of ethanol, energy drink (stimulant), complementary and alternative therapies, and tobacco use, prior treatment for cancer, prematurity and genetic disorders. These should all be evaluated and considered prior to initiating cardiotoxic cancer therapies to identify high-cardiovascular-risk populations for treatment to reduce this risk by modification of these risk factors, using cardioprotective strategies, and by minimizing the use of, or avoiding, cardiotoxic cancer therapies.

Independently of these risk factors, not all children and adolescents exposed to toxic treatments, even those who receive the same standardized chemotherapeutic regimens, experience cardiotoxicity, suggesting the possibility of a genetic predisposition [20, 22, 23]. For example, hereditary hemochromatosis is a genetic disorder associated with a mutation of the Hfe gene, which encodes the human hemochromatosis protein, a protein that interferes with iron metabolism and leads to iron overload and increases susceptibility to anthracycline-associated toxicity [24]. An animal study in doxorubicin-treated mice showed that $\mathrm{Hfe}$ knockout mice $\left(\mathrm{Hfe}^{-/-}\right)$displayed a higher degree of mitochondrial damage and iron deposits in the heart than did wild-type mice $[24,25]$.

As described above, anthracyclines form complexes with intracellular iron, which result in free radical forma-

Cardioprotection in Childhood Cancer Survivors tion; therefore, iron accumulating in the heart increases the susceptibility to doxorubicin-induced cardiotoxicity. In a recent study of long-term survivors of childhood high-risk acute lymphoblastic leukemia, $10 \%$ of survivors were carriers of a mutation in the C282Y allele, one of the mutations most commonly associated with $\mathrm{Hfe}$ [24]. Furthermore, the risk of myocardial injury in survivors who were heterozygous for the C282Y allele was 9 times higher than that in noncarriers [24]. Blanco et al. [26] found that among patients with single nucleotide polymorphisms in CBR3 homozygous $\mathrm{G}$ genotypes (CBR3:GG), exposure to low-to-moderate doses of anthracyclines increased the risk of cardiomyopathy by 5 and 3 times that of survivors with the CBR3:GA/AA genotypes unexposed and exposed to low-to-moderate-dose anthracyclines, respectively. Polymorphisms in CBR3 influence the synthesis of carbonyl reductases, which catalyze the reduction of anthracyclines to cardiotoxic alcohol metabolites [26]. These studies show the potential influence of genetics in identifying patients at an increased risk of anthracyclineinduced cardiac effects; however, additional studies specifically designed to address and confirm these novel risk factors are needed.

Obesity is a well-known cardiac risk factor [27]. Compared with siblings, male survivors have a greater body fat and metabolic risk. Cranial irradiation and television hours are important risk factors for adiposity in pediatric cancer survivors [28]. In a study assessing the dietary trends of childhood cancer survivors, it was found that survivors consumed diets that only moderately adhered to current recommendations [29]. Dietary quality below current recommendations often leads to increased adiposity, increasing the risk for cardiovascular disease [29]. Targeting dietary consumption can decrease adiposity and lower cardiovascular risk. Furthermore, supervised physical activity should be encouraged to improve nutritional and cardiac conditions [30].

Klosky et al. [31] looked at childhood cancer survivors aged 14-20 years and found no significant difference between usage rates of tobacco, alcohol and illicit drugs, or risky sexual behavior when compared to sibling controls. Kahalley et al. [32] also found no significant difference in smoking rates between childhood cancer survivors and healthy sibling controls. However, Kahalley et al. did address the correlation between the increased incidence of smoking and health risk factors, such as peer smoking, household smoking and suicidal behavior. The risk factors noted by Kahalley et al., in addition to smoking, which is already an established risk factor for cardiovascular disease, put this patient popu- 
lation into a high-risk group, and they should be counseled accordingly [33].

The sex of the patient also appears to be a risk factor for cardiotoxicity. Females have higher rates of LV dysfunction than do males exposed to similar doses of doxorubicin [34]. The cause of this increased risk associated with females is not clear. It is hypothesized that because doxorubicin does not reach a high concentration in adipose tissue, females generally have a higher percent body fat and anthracycline dosages are calculated based on body surface area, female cardiomyocytes may be exposed to a higher concentration when compared to cardiomyocyte intracellular concentrations in males [35].

\section{Monitoring and Screening}

Evidence-based monitoring and screening of childhood cancer survivors is imperative in identifying early signs of cardiotoxicity in patients who may be at higher risk. Aside from obtaining a thorough medical history, baseline cardiac studies are recommended before beginning chemotherapy [36-38]. Although endomyocardial biopsy may provide useful histological information, serial biopsies are not only expensive, but also highly invasive.

Newer studies of serum cardiac biomarkers are showing promise. These biomarkers may identify several different populations, including those experiencing cardiotoxicity, as well as those who may develop future cardiotoxicity. Lipshultz et al. [39] evaluated children with acute lymphoblastic leukemia treated with doxorubicin. They monitored concentrations of cardiac troponin $\mathrm{T}$, $\mathrm{N}$-terminal probrain natriuretic peptide (NT-proBNP) and high-sensitivity C-reactive protein. Serum cardiac troponin $\mathrm{T}$ concentrations elevated in the first 90 days of treatment with anthracyclines were significantly associated with reduced LV end-diastolic posterior wall thickness, reduced LV mass and increased LV remodeling 4 years after therapy [39]. Serum NT-proBNP concentrations may indicate increasing LV wall stress, as this level rises with wall stretch. NT-proBNP concentrations were elevated in $89 \%$ of patients before treatment and in $48 \%$ of patients after treatment [39]. Overall, NT-proBNP was elevated in more patients than was cardiac troponin $\mathrm{T}$, which may identify patients at risk for future cardiotoxicity, and significantly predicted late LV remodeling [39]. The authors did not find elevated high-sensitivity C-reactive protein concentrations measured during anthracycline therapy to be a reliable marker for patients who may develop late cardiotoxicity as long-term survivors [39].

Additionally, as assessment of LV diastolic function and cardiac magnetic resonance imaging are increasingly used in pediatric cardiology, adolescent patients may benefit from its ability to identify cardiotoxicity. However, limited availability of diastolic function measurements and the availability, accessibility, high cost and lengthy studies may potentially limit widespread cardiac magnetic resonance usage.

\section{Preventing Cardiotoxicity}

Given the risk of cardiotoxicity with anthracyclines, various strategies to limit cardiac injury without reducing oncological efficacy have been explored. These are summarized below.

\section{Continuous versus Bolus Anthracycline Infusion}

In adults, cardiotoxicity assessed early after anthracycline infusion is reduced by continuous infusion, which lowers peak plasma levels in comparison with bolus infusions [40]. However, these same results were not replicated in a large prospective randomized controlled trial of children with a diagnosis of high-risk acute lymphoblastic leukemia [41]. Neither outcome with LV function nor 10-year event-free survival differed significantly between groups receiving either continuous or bolus infusion $[41,42]$. This study suggests that continuous infusion of anthracyclines does not provide cardioprotection over bolus infusion in children [41].

\section{Structural Modifications of Anthracyclines}

Modifying the structural form of anthracyclines to reduce their cardiotoxicity is another experimental approach. Epirubicin, a structural analog of doxorubicin, has less overall toxicity but the same efficacy as doxorubicin. A cumulative dose of epirubicin up to $900 \mathrm{mg} / \mathrm{m}^{2}$ is equivalent to only $450 \mathrm{mg} / \mathrm{m}^{2}$ of doxorubicin in terms of cardiotoxicity [43].

Two separate studies of patients with breast cancer showed that epirubicin had a less toxic profile than doxorubicin $[44,45]$. A meta-analysis of 5 randomized control trials comparing epirubicin to doxorubicin found no significant difference in the incidence of early clinical heart failure between control and experimental groups [46]. However, on the basis of a wide confidence interval and a low relative risk, this meta-analysis suggested a lower rate of clinical heart failure in the epirubicin treatment 
group [46]. All these studies were limited to adults with solid tumors. Response rates did not differ between groups [46]. In a separate study, also in adults, lower doses of epirubicin up to $360 \mathrm{mg} / \mathrm{m}^{2}$ have also caused subclinical cardiotoxicity [47].

Other doxorubicin analogs, idarubicin and mitoxantrone, although they may reduce cardiac injury, do not completely eliminate the risk of cardiotoxicity [43, 48]. Studies with use of these different analogs have so far been done only in adults with breast cancer [47, 48]. To our knowledge, no studies have been conducted in adolescents that might justify the use of analogs in this group.

\section{Liposomal Anthracyclines}

Liposomal anthracyclines have a better and safer oncological profile than do conventional anthracyclines [49]. Two forms of liposomal anthracyclines are currently available: pegylated PL-ODX/Doxil/Caelyx and nonpegylated Tl-D99/Myocet.

Pegylated anthracyclines, compared to regular anthracyclines, have longer circulation times, longer half-lives, slower clearance from plasma, a smaller volume of distribution and they cannot penetrate cardiac cell tight junctions $[50,51]$. These characteristics result in higher drug concentrations in tumors and lower concentrations in the heart [51]. Therefore, pegylated anthracyclines decrease cardiotoxicity while maintaining oncological efficacy. This conclusion was supported by endomyocardial biopsies of patients receiving liposomal versus conventional anthracyclines [49].

Another retrospective study showed that cumulative doses of the pegylated form, up to $500 \mathrm{mg} / \mathrm{m}^{2}$, did not result in heart failure [52]. A meta-analysis of 2 other randomized controlled trials in women with metastatic breast cancer found fewer clinical and subclinical cardiac events in the group receiving liposomal anthracyclines [46]. However, no randomized controlled trials in children have been conducted to reproduce these results [51].

Only 1 randomized trial studied the use of liposomal daunorubicin as a second-line therapy in children with relapsed acute myeloid leukemia [53]. However, interpreting cardiac damage in this population is difficult because the patients had already undergone aggressive firstline therapy.

\section{Use of Cardioprotective Agents}

Dexrazoxane

Dexrazoxane is an iron-chelating agent that reduces the formation of iron-anthracycline complexes [54, 55]. Without these iron-anthracycline complexes, the genera-

Cardioprotection in Childhood Cancer

Survivors tion of reactive oxygen species is limited, thus limiting the toxicity of anthracyclines $[54,55]$. Dexrazoxane also interferes with topoisomerase $2 \beta$, thereby antagonizing doxorubicin-induced DNA damage [56].

A randomized controlled trial by Lipshultz et al. [54] compared children less than 18 years of age with a diagnosis of high-risk acute lymphoblastic leukemia receiving doxorubicin alone with those receiving treatment with dexrazoxane and doxorubicin. The cardiac damage, as measured by serum cardiac troponin concentrations, was significantly less in the group receiving dexrazoxane [54]. Girls treated with doxorubicin and dexrazoxane had better long-term outcomes in terms of LV fractional shortening, LV end-diastolic dimension, LV posterior wall thickness and LV pathological remodeling measurements [55]. At the same time, the rate of secondary neoplasms and 8 -year event-free survival was similar, whether or not children received dexrazoxane with doxorubicin [55].

A meta-analysis by Van Dalen et al. [57] revealed statistically lower rates of heart failure in children and adult patients who had been treated with dexrazoxane when compared to those who had not. The two groups did not differ significantly in antioncological effects or in survival rates [57]. The American Society of Clinical Oncology recommends dexrazoxane in adult patients with metastatic breast cancer being treated with anthracyclines in cumulative doses greater than $300 \mathrm{mg} / \mathrm{m}^{2}$ [58].

\section{Carvedilol}

Carvedilol provides cardioprotection by inhibiting reactive oxygen species, scavenging free radicals, preventing lipid peroxidation and increasing vitamin E concentrations [59]. Some of these mechanisms have been documented in in vitro studies [60]. Carvedilol reduced anthracycline-induced cardiomyopathy in rats [61]. This evidence further needs to be supported in human studies [61].

\section{Supplements}

\section{Coenzyme Q}

Coenzyme Q, an antioxidant, is an important part of the mitochondrial respiratory chain [62]. Supplementation of coenzyme $\mathrm{Q}$ prevented anthracycline-induced cardiotoxicity in both preclinical and clinical studies [62]. Currently, only 1 study has shown that coenzyme Q treatment has reduced the incidence of cardiotoxicity in children treated with doxorubicin [63].

\section{L-Carnitine}

The naturally occurring amino acid L-carnitine protects the heart from damage by its antioxidant action against an- 


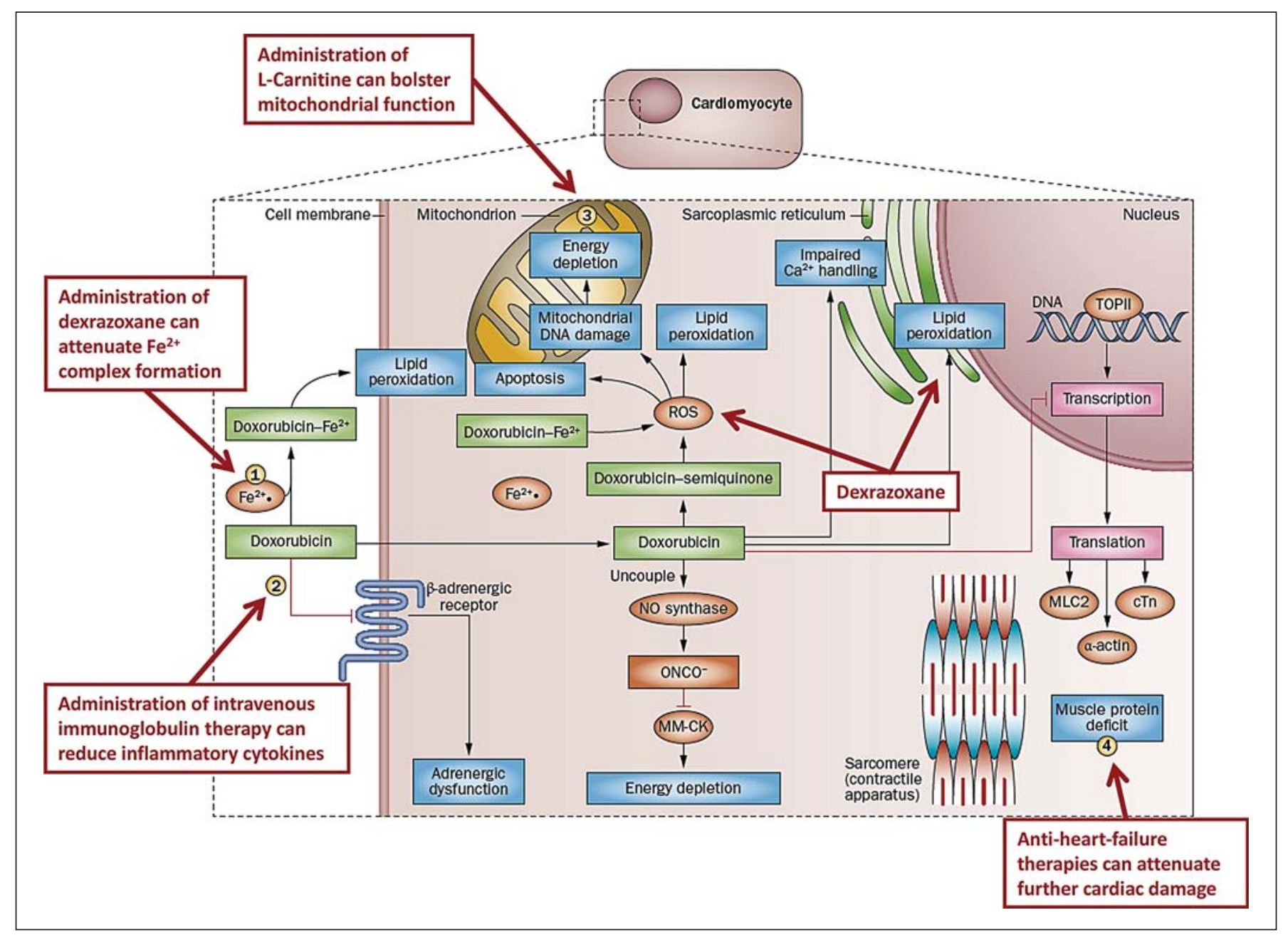

Fig. 1. Potential opportunities for targeted multiagent cardioprotection. Doxorubicin chemotherapy has a range of effects on cardiomyocytes. It induces lipid peroxidation at the cell and mitochondrial membranes by way of complexing with $\mathrm{Fe}^{2+}$ and induces apoptosis, mitochondrial DNA damage and energy depletion through its production of reactive oxygen species. Furthermore, it impairs $\mathrm{Ca}^{2+}$ processing in the sarcoplasmic reticulum and inhibits the transcription of important muscle elements, weakening the heart muscle. It also downregulates adrenergic receptors and interrupts cell signaling. We have explored 4 areas for multiagent anthracycline cardioprotection, but other mechanisms and potential targets exist as well. This figure illustrates the 4 areas we have fo-

thracycline-induced lipid peroxidation of cardiac membranes and by reducing the ability of anthracyclines to inhibit long-chain fatty acid production [58]. Therefore, Lcarnitine supplementation should protect against the acute and chronic effects of anthracycline-induced cardiotoxicity. However, there is insufficient evidence to justify the conclusion that L-carnitine is cardioprotective $[46,64]$. cused on and their potential cardioprotective mechanisms and includes: (1) administration of dexrazoxane, which can prevent $\mathrm{Fe}^{2+}$ complex formation; (2) intravenous immunoglobulin therapy, which can reduce inflammatory cytokines; (3) L-carnitine, which can bolster mitochondrial function, and (4) anti-heart-failure therapies, such as angiotensin-converting enzyme inhibitors and $\beta$-blockers, which can prevent further damage and pathological ventricular remodeling. $\mathrm{cTn}=$ Cardiac troponin; $\mathrm{MLC} 2=$ myosin light chain 2; MM-CK = myofibrillar isoform of the creatine kinase enzyme; $\mathrm{NO}=$ nitric oxide; $\mathrm{ROS}$ = reactive oxygen species; TOPII $=$ topoisomerase 2 . Modified with permission from Lipshultz et al. [70] in Nature Publishing Group.

\section{Glutathione}

Glutathione, a tripeptide thiol, is another antioxidant that scavenges free radicals. It acts as a substrate for glutathione peroxidase whose activity is interfered with by anthracyclines [65]. Thus, glutathione supplementation may protect the heart from anthracycline effects [58]. Both in vitro and animal studies have shown that gluta- 
thione supplementation decreases cardiac damage [6669]. Glutathione does have potential in preventing anthracycline-induced cardiac damage.

\section{Conclusion}

Advancements in cancer therapies have undoubtedly contributed to the improved life expectancy of childhood cancer survivors. However, despite this increased survival, many survivors have a lower quality of life as a result of the adverse late effects of the same treatments that cured their cancer. Exposure to these treatments of children at a young age makes them particularly vulnerable to impaired growth and development and to an increased risk of premature cardiovascular disease. Screening for risk factors, including genetic risk factors such as $\mathrm{Hfe}$, together with serum biomarkers, might prove useful at early stages to inform treatment decisions. However, the mechanisms of anthracycline- and radiation-induced cardiotoxicity need to be better understood to develop effective and safe cardioprotective strategies. Nevertheless, an effective cardioprotective agent, dexrazoxane, has been validated in children receiving anthracycline chemotherapy and should be incorporated into clinical trials where children with cancer receive anthracycline chemotherapy. Additional cardioprotective strategies may allow for multiagent cardioprotection to maximize oncological efficacy while minimizing toxicity and late adverse effects (fig. 1). This is particularly important since the successful treatment of childhood cancer brings about the overall quality of life during a lifespan as determined by the balance between efficacy and late effects.

\section{References}

1 American Cancer Society: Cancer Facts and Figures 2012. Atlanta, American Cancer Society, 2012.

2 Howlader N, Noone AM, Krapcho M, Garshell J, Neyman N, Altekruse SF, Kosary CL, Yu M, Ruhl J, Tatalovich Z, Cho H, Mariotto A, Lewis DR, Chen HS, Feuer EJ, Cronin KA (eds): SEER Cancer Statistics Review, 1975-2010. Bethesda, National Cancer Institute. http://seer.cancer.gov/csr/1975_2010/ (based on November 2012 SEER data submission, posted to the SEER web site, April 2013).

>3 Oeffinger KC, Mertens AC, Sklar CA, Kawashima T, Hudson MM, Meadows AT, Friedman DL, Marina N, Hobbie W, KadanLottick NS, Schwartz CL, Leisenring W, Robison LL; Childhood Cancer Survivor Study: Chronic health conditions in adult survivors of childhood cancer. N Engl J Med 2006;355: 1572-1582.

$\checkmark 4$ Mulrooney DA, Yeazel MW, Kawashima T, Mertens AC, Mitby P, Stovall M, Donaldson SS, Green DM, Sklar CA, Robison LL, Leisenring WM: Cardiac outcomes in a cohort of adult survivors of childhood and adolescent cancer: retrospective analysis of the Childhood Cancer Survivor Study cohort. BMJ 2009;339:b4606.

$\checkmark 5$ Tukenova M, Guibout C, Oberlin O, Doyon F, Mousannif A, Haddy N, Guérin S, Pacquement H, Aouba A, Hawkins M, Winter D, Bourhis J, Lefkopoulos D, Diallo I, de Vathaire F: Role of cancer treatment in long-term overall and cardiovascular mortality after childhood cancer. J Clin Oncol 2010;28:13081315.
6 Armstrong GT, Oeffinger KC, Chen Y, Kawashima T, Yasui Y, Leisenring W, Stovall M, Chow EJ, Sklar CA, Mulrooney DA, Mertens AC, Border W, Durand JB, Robison LL, Meacham LR: Modifiable risk factors and major cardiac events among adult survivors of childhood cancer. J Clin Oncol 2013;31:3673-3680.

7 Lipshultz SE, Colan SD, Gelber RD, PerezAtayde AR, Sallan SE, Sanders SP: Late cardiac effects of doxorubicin therapy for acute lymphoblastic leukemia in childhood. N Engl J Med 1991;324:808-815.

-8 Landy DC, Miller TL, Lipsitz SR, Lopez-Mitnik G, Hinkle AS, Constine LS, Adams MJ, Lipshultz SE: Cranial irradiation as an additional risk factor for anthracycline cardiotoxicity in childhood cancer survivors: an analysis from the cardiac risk factors in childhood cancer survivors study. Pediatr Cardiol 2013; 34:826-834.

$\checkmark 9$ Adão R, de Keulenaer G, Leite-Moreira A, Brás-Silva C: Cardiotoxicity associated with cancer therapy: pathophysiology and prevention. Rev Portug Cardiol (English ed) 2013;32: 395-409.

10 Diamond M, Franco V: Preventing and treating anthracycline-related cardiotoxicity in survivors of childhood cancer. Curr Cancer Ther Rev 2012;8:141-151.

-11 Franco VI, Henkel JM, Miller TL, Lipshultz SE: Cardiovascular effects in childhood cancer survivors treated with anthracyclines. Cardiol Res Pract 2011;2011:134679.

12 Dillenburg RF, Nathan P, Mertens L: Educational paper: decreasing the burden of cardiovascular disease in childhood cancer survivors: an update for the pediatrician. Eur J Pediatr 2013;172:1149-1160.
13 Von Hoff DD, Layard MW, Basa P, Davis HL Jr, Von Hoff AL, Rozencweig M, Muggia FM: Risk factors for doxorubicin-induced congestive heart failure. Ann Intern Med 1979;91: 710-717.

14 Nysom K, Holm K, Lipsitz SR, Mone SM, Colan SD, Orav EJ, Sallan SE, Olsen JH, Hertz H, Jacobsen JR, Lipshultz SE: Relationship between cumulative anthracycline dose and late cardiotoxicity in childhood acute lymphoblastic leukemia. J Clin Oncol 1998;16:545550 .

15 Vandecruys E, Mondelaers V, De Wolf D, Benoit Y, Suys B: Late cardiotoxicity after low dose of anthracycline therapy for acute lymphoblastic leukemia in childhood. J Cancer Surviv 2012;6:95-101.

16 Lipshultz SE, Adams MJ: Cardiotoxicity after childhood cancer: beginning with the end in mind. J Clin Oncol 2010;28:1276-1281.

-17 Van der Pal HJ, van Dalen EC, Hauptmann M, Kok WE, Caron HN, van den Bos C, Oldenburger F, Koning CC, van Leeuwen FE, Kremer LC: Cardiac function in 5-year survivors of childhood cancer: a long-term followup study. Arch Intern Med 2010;170:12471255.

18 Swain SM, Whaley FS, Ewer MS: Congestive heart failure in patients treated with doxorubicin: a retrospective analysis of three trials. Cancer 2003;97:2869-2879.

19 Lipshultz SE, Lipsitz SR, Sallan SE, Dalton VM, Mone SM, Gelber RD, Colan SD: Chronic progressive cardiac dysfunction years after doxorubicin therapy for childhood acute lymphoblastic leukemia. J Clin Oncol 2005;23: 2629-2636. 
20 Krischer JP, Epstein S, Cuthbertson DD, Goorin AM, Epstein ML, Lipshultz SE: Clinical cardiotoxicity following anthracycline treatment for childhood cancer: the Pediatric Oncology Group experience. J Clin Oncol 1997;15:1544-1552.

21 Wang L, Weinshilboum R: Thiopurine Smethyltransferase pharmacogenetics: insights, challenges and future directions. Oncogene 2006;25:1629-1638.

22 Deng S, Wojnowski L: Genotyping the risk of anthracycline-induced cardiotoxicity. Cardiovasc Toxicol 2007;7:129-134.

23 Blanco JG, Leisenring WM, Gonzalez-Covarrubias VM, Kawashima TI, Davies SM, Relling MV, Robison LL, Sklar CA, Stovall M, Bhatia S: Genetic polymorphisms in the carbonyl reductase 3 gene CBR3 and the $\mathrm{NAD}(\mathrm{P}) \mathrm{H}$ : quinone oxidoreductase 1 gene NQO1 in patients who developed anthracycline-related congestive heart failure after childhood cancer. Cancer 2008;112:27892795.

-24 Lipshultz SE, Lipsitz SR, Kutok JL, Miller TL, Colan SD, Neuberg DS, Stevenson KE, Fleming MD, Sallan SE, Franco VI, Henkel JM, Asselin BL, Athale UH, Clavell LA, Michon B, Laverdiere C, Larsen E, Kelly KM, Silverman LB: Impact of hemochromatosis gene mutations on cardiac status in doxorubicin-treated survivors of childhood high-risk leukemia. Cancer 2013;119:3555-3562.

-25 Miranda CJ, Makui H, Soares RJ, Bilodeau M, Mui J, Vali H, Bertrand R, Andrews NC, Santos MM: $\mathrm{Hfe}$ deficiency increases susceptibility to cardiotoxicity and exacerbates changes in iron metabolism induced by doxorubicin. Blood 2003;102:2574-2580.

-26 Blanco JG, Sun CL, Landier W, Chen L, Esparza-Duran D, Leisenring W, Mays A, Friedman DL, Ginsberg JP, Hudson MM, Neglia JP, Oeffinger KC, Ritchey AK, Villaluna D, Relling MV, Bhatia S: Anthracycline-related cardiomyopathy after childhood cancer: role of polymorphisms in carbonyl reductase genes - a report from the Children's Oncology Group. J Clin Oncol 2012;30:1415-1421.

-27 Qureshi MY, Wilkinson JD, Lipshultz SE: The relationship of childhood obesity with cardiomyopathy and heart failure; in Lipshultz SE, Messiah SE, Miller TL (eds): Pediatric Metabolic Syndrome. London, Springer, 2012, pp 199-215.

-28 Miller TL, Lipsitz SR, Lopez-Mitnik G, Hinkle AS, Constine LS, Adams MJ, French C, Proukou C, Rovitelli A, Lipshultz SE: Characteristics and determinants of adiposity in pediatric cancer survivors. Cancer Epidemiol Biomarkers Prev 2010;19:2013-2022.

29 Landy DC, Lipsitz SR, Kurtz JM, Hinkle AS, Constine LS, Adams MJ, Lipshultz SE, Miller TL: Dietary quality, caloric intake, and adiposity of childhood cancer survivors and their siblings: an analysis from the Cardiac Risk Factors in Childhood Cancer Survivors Study. Nutr Cancer 2013;65:547-555.
30 Miller AM, Lopez-Mitnik G, Somarriba G, Lipsitz SR, Hinkle AS, Constine LS, Lipshultz SE, Miller TL: Exercise capacity in long-term survivors of pediatric cancer: an analysis from the Cardiac Risk Factors in Childhood Cancer Survivors Study. Pediatr Blood Cancer 2013; 60:663-668.

- 31 Klosky JL, Howell CR, Li Z, Foster RH, Mertens AC, Robison LL, Ness KK: Risky health behavior among adolescents in the Childhood Cancer Survivor Study cohort. J Pediatr Psychol 2012;37:634-646.

32 Kahalley LS, Robinson LA, Tyc VL, Hudson MM, Leisenring W, Stratton K, Mertens AC, Zeltzer L, Robison LL, Hinds PS: Risk factors for smoking among adolescent survivors of childhood cancer: a report from the Childhood Cancer Survivor Study. Pediatr Blood Cancer 2012;58:428-434.

33 Lakier JB: Smoking and cardiovascular disease. Am J Med 1992;93(1A):8S-12S.

- 34 Silber JH, Jakacki RI, Larsen RL, Goldwein JW, Barber G: Increased risk of cardiac dysfunction after anthracyclines in girls. Med $\mathrm{Pe}$ diatr Oncol 1993;21:477-479.

35 Lipshultz SE, Lipsitz SR, Mone SM, Goorin AM, Sallan SE, Sanders SP, Orav EJ, Gelber RD, Colan SD: Female sex and drug dose as risk factors for late cardiotoxic effects of doxorubicin therapy for childhood cancer. N Engl J Med 1995;332:1738-1743.

-36 Bovelli D, Plataniotis G, Roila F: Cardiotoxicity of chemotherapeutic agents and radiotherapy-related heart disease: ESMO Clinical Practice Guidelines. Ann Oncol 2010;21 (suppl 5):v277-v282.

37 Trachtenberg BH, Landy DC, Franco VI, Henkel JM, Pearson EJ, Miller TL, Lipshultz SE: Anthracycline-associated cardiotoxicity in survivors of childhood cancer. Pediatr Cardiol 2011;32:342-353.

38 Gottsauner-Wolf M, Schedlmayer-Duit J, Porenta G, Gwechenberger M, Huber K, Glogar D, Probst P, Sochor H: Assessment of left ventricular function: comparison between radionuclide angiography and semiquantitative two-dimensional echocardiographic analysis. Eur J Nucl Med 1996;23:1613-1618.

39 Lipshultz SE, Miller TL, Scully RE, Lipsitz SR, Rifai N, Silverman LB, Colan SD, Neuberg DS, Dahlberg SE, Henkel JM, Asselin BL, Athale UH, Clavell LA, Laverdière C, Michon B, Schorin MA, Sallan SE: Changes in cardiac biomarkers during doxorubicin treatment of pediatric patients with high-risk acute lymphoblastic leukemia: associations with longterm echocardiographic outcomes. J Clin Oncol 2012;30:1042-1049.

40 Legha SS, Benjamin RS, Mackay B, Ewer M, Wallace S, Valdivieso M, Rasmussen SL, Blumenschein GR, Freireich EJ: Reduction of doxorubicin cardiotoxicity by prolonged continuous intravenous infusion. Ann Intern Med 1982;96:133-139.
41 Lipshultz SE, Miller TL, Lipsitz SR, Neuberg DS, Dahlberg SE, Colan SD, Silverman LB, Henkel JM, Franco VI, Cushman LL, Asselin BL, Clavell LA, Athale U, Michon B, Laverdière C, Schorin MA, Larsen E, Usmani N, Sallan SE; Dana-Farber Cancer Institute Acute Lymphoblastic Leukemia Consortium: Continuous versus bolus infusion of doxorubicin in children with ALL: long-term cardiac outcomes. Pediatrics 2012;130:1003-1011.

42 Lipshultz SE, Giantris AL, Lipsitz SR, Kimball Dalton V, Asselin BL, Barr RD, Clavell LA, Hurwitz CA, Moghrabi A, Samson Y, Schorin MA, Gelber RD, Sallan SE, Colan SD: Doxorubicin administration by continuous infusion is not cardioprotective: the Dana-Farber 91-01 Acute Lymphoblastic Leukemia protocol. J Clin Oncol 2002;20:1677-1682.

-43 Barry E, Alvarez JA, Scully RE, Miller TL, Lipshultz SE: Anthracycline-induced cardiotoxicity: course, pathophysiology, prevention and management. Expert Opin Pharmacother 2007;8:1039-1058.

44 French Epirubicin Study Group: A prospective randomized phase III trial comparing combination chemotherapy with cyclophosphamide, fluorouracil, and either doxorubicin or epirubicin. J Clin Oncol 1988;6:679688.

45 Phase III randomized study of fluorouracil, epirubicin, and cyclophosphamide versus fluorouracil, doxorubicin, and cyclophosphamide in advanced breast cancer: an Italian multicentre trial. Italian Multicentre Breast Study with Epirubicin. J Clin Oncol 1988;6: 976-982.

46 Van Dalen EC, Michiels EM, Caron HN, Kremer LC: Different anthracycline derivates for reducing cardiotoxicity in cancer patients. Cochrane Database Syst Rev 2010;5: CD005006.

47 Meinardi MT, van Veldhuisen DJ, Gietema JA, Dolsma WV, Boomsma F, van den Berg MP, Volkers C, Haaksma J, de Vries EG, Sleijfer DT, van der Graaf WT: Prospective evaluation of early cardiac damage induced by epirubicin-containing adjuvant chemotherapy and locoregional radiotherapy in breast cancer patients. J Clin Oncol 2001;19:2746-2753.

48 Cowan JD, Neidhart J, McClure S, Coltman CA Jr, Gumbart C, Martino S, Hutchins LF, Stephens RL, Vaughan CB, Osborne CK: Randomized trial of doxorubicin, bisantrene, and mitoxantrone in advanced breast cancer: a Southwest Oncology Group study. J Natl Cancer Inst 1991;83:1077-1084.

49 Gabizon AA, Lyass O, Berry GJ, Wildgust M: Cardiac safety of pegylated liposomal doxorubicin (Doxil/Caelyx) demonstrated by endomyocardial biopsy in patients with advanced malignancies. Cancer Invest 2004;22: 663-669.

50 Leonard RC, Williams S, Tulpule A, Levine AM, Oliveros S: Improving the therapeutic index of anthracycline chemotherapy: focus on liposomal doxorubicin (Myocet). Breast 2009;18:218-224. 
-51 Sieswerda E, Kremer LC, Caron HN, van Dalen EC: The use of liposomal anthracycline analogues for childhood malignancies: a systematic review. Eur J Cancer 2011;47:20002008.

52 Safra T, Muggia F, Jeffers S, Tsao-Wei DD, Lyass O, Henderson R, Berry G, Gabizon A: Pegylated liposomal doxorubicin (Doxil): reduced clinical cardiotoxicity in patients reaching or exceeding cumulative doses of 500 mg/m². Ann Oncol 2000;11:1029-1033.

53 Kaspers GJ, Zimmermann M, Reinhardt D, Gibson BE, Tamminga RY, Aleinikova O, Armendariz H, Dworzak M, Ha SY, Hasle H, Hovi L, Maschan A, Bertrand Y, Leverger GG, Razzouk BI, Rizzari C, Smisek P, Smith O, Stark B, Creutzig U: Improved outcome in pediatric relapsed acute myeloid leukemia: results of a randomized trial on liposomal daunorubicin by the International BFM Study Group. J Clin Oncol 2013;31:599-607.

-54 Lipshultz SE, Rifai N, Dalton VM, Levy DE, Silverman LB, Lipsitz SR, Colan SD, Asselin BL, Barr RD, Clavell LA, Hurwitz CA, Moghrabi A, Samson Y, Schorin MA, Gelber RD, Sallan SE: The effect of dexrazoxane on myocardial injury in doxorubicin-treated children with acute lymphoblastic leukemia. N Engl J Med 2004;351:145-153.

55 Lipshultz SE, Scully RE, Lipsitz SR, Sallan SE, Silverman LB, Millter TL, Barry EV, Asselin BL, Athale U, Clavell LA, Larsen E, Moghrabi A, Samson Y, Michon B, Schorin MA, Cohen HJ, Neuberg DS, Orav EJ, Colan SD: Assessment of dexrazoxane as a cardioprotectant in doxorubicin-treated children with high-risk acute lymphoblastic leukaemia: long-term follow-up of a prospective, randomised, multicentre trial. Lancet Oncol 2010;11:950-961.
56 Lyu YL, Kerrigan JE, Lin CP, Azarova AM, Tsai YC, Ban Y, Liu LF: Topoisomerase II-beta mediated DNA double-strand breaks: implications in doxorubicin cardiotoxicity and prevention by dexrazoxane. Cancer Res 2007; 67:8839-8846.

57 Van Dalen EC, Caron HN, Dickinson HO, Kremer LC: Cardioprotective interventions for cancer patients receiving anthracyclines. Cochrane Database Syst Rev 2011;6: CD003917.

58 Wouters KA, Kremer LC, Miller TL, Herman EH, Lipshultz SE: Protecting against anthracycline-induced myocardial damage: a review of the most promising strategies. Br J Haematol 2005; 131:561-578.

59 Feuerstein GZ, Ruffolo RR Jr: Carvedilol, a novel multiple action antihypertensive agent with antioxidant activity and the potential for myocardial and vascular protection. Eur Heart J 1995;16(suppl F):38-42.

60 Spallarossa P, Garibaldi S, Altieri P, Fabbi P, Manca V, Nasti S, Rossettin P, Ghigliotti G, Ballestrero A, Patrone F, Barsotti A, Brunelli C: Carvedilol prevents doxorubicin-induced free radical release and apoptosis in cardiomyocytes in vitro. J Mol Cell Cardiol 2004;37: 837-846.

61 Matsui H, Morishima I, Numaguchi Y, Toki Y, Okumura K, Hayakawa T: Protective effects of carvedilol against doxorubicin-induced cardiomyopathy in rats. Life Sci 1999; 65:1265-1274.

62 Granados-Principal S, Quiles JL, RamirezTortosa CL, Sanchez-Rovira P, Ramirez-Tortosa MC: New advances in molecular mechanisms and the prevention of Adriamycin toxicity by antioxidant nutrients. Food Chem Toxicol 2010;48:1425-1438.
63 Iarussi D, Auricchio U, Agretto A, Murano A, Giuliano M, Casale F, Indolfi P, Iacono A: Protective effect of coenzyme $\mathrm{Q}_{10}$ on anthracyclines cardiotoxicity: control study in children with acute lymphoblastic leukemia and non-Hodgkin lymphoma. Mol Aspects Med 1994;15(suppl):s207-s212.

64 De Leonardis V, Neri B, Bacalli S, Cinelli P. Reduction of cardiac toxicity of anthracyclines by L-carnitine: preliminary overview of clinical data. Int J Clin Pharmacol Res 1985;5: 137-142.

65 Doroshow JH, Locker GY, Myers CE: Enzymatic defenses of the mouse heart against reactive oxygen metabolites: alterations produced by doxorubicin. J Clin Invest 1980;65: 128-135.

66 Arrick BA, Nathan CF, Griffith OW, Cohn ZA: Glutathione depletion sensitizes tumor cells to oxidative cytolysis. J Biol Chem 1982; 257:1231-1237.

67 Suttorp N, Toepfer W, Roka L: Antioxidant defense mechanisms of endothelial cells: glutathione redox cycle versus catalase. Am J Physiol 1986;251:C671-C680.

68 Mohamed HE, El-Swefy SE, Hagar HH: The protective effect of glutathione administration on Adriamycin-induced acute cardiac toxicity in rats. Pharmacol Res 2000;42:115121.

-69 Ferrari R, Ceconi C, Curello S, Cargnoni A, Alfieri O, Pardini A, Marzollo P, Visioli O: Oxygen free radicals and myocardial damage: protective role of thiol-containing agents. Am J Med 1991;91(3C):95S-105S.

70 Lipshultz SE, Cochran TR, Franco VI, Miller TL: Treatment-related cardiotoxicity in survivors of childhood cancer. Nat Rev Clin Oncol 2013;10:697-710. 